\title{
Electrochemical and Mechanical Properties of Cast Ti-V Alloys for Dental Applications
}

Kyung Hee Park, Moon-Jin Hwang, Ho-Jun Song and Yeong-Joon Park ${ }^{*}$

Department of Dental Materials and Medical Research Center for Biomineralization Disorders, School of Dentistry, Chonnam National University, Gwangju 61186, Korea

E-mail: yjpark@jnu.ac.kr

doi: $10.20964 / 2016.07 .64$

Received: 6 April 2016 / Accepted: 12 May 2016 / Published: 4 June 2016

A series of Ti- $x \mathrm{~V}$ alloys with a vanadium (V) content ranging from 5 to $20 \mathrm{wt} \%$ were fabricated to investigate phase/microstructure, various mechanical, and electrochemical properties. The microstructural samples were characterized using X-ray diffractometry (XRD), scanning electron microscopy (SEM) and transmission electron microscopy (TEM). All the Ti- $x \mathrm{~V}$ alloys showed colonies of hexagonal close packed (hcp) $\alpha$-phase lamellae within large body centered cubic (bcc) $\beta$ phase grains of several lath boundaries. As a result of solid-solution strengthening of $\alpha-\mathrm{Ti}$ and $\beta-\mathrm{Ti}$ phase matrix, the Ti- $x \mathrm{~V}$ showed better mechanical properties than the commercially pure titanium (cpTi). Based on the electrochemical results, the Ti-5V alloy exhibited improved corrosion resistance as compared with cp-Ti.

Keywords: Ti-V alloy, mechanical properties, electrochemical properties, dental materials

\section{FULL TEXT}

(C) 2016 The Authors. Published by ESG (www.electrochemsci.org). This article is an open access article distributed under the terms and conditions of the Creative Commons Attribution license (http://creativecommons.org/licenses/by/4.0/). 